\title{
NOTE ON TRANSCRIPTION AND EDITING
}

Accidental omissions in the text have been supplied, and repetitions and erasures have been noted, in footnotes. Interlineations of his own omissions by the original scribe have been incorporated into the text without any special note, but additions by a later hand have been noted. In the cases where an original charter survives, the reading of this has been adopted, and any cartulary variations supplied as a footnote. The use of the Tironian sign (7) for $e t$ and all original punctuation and stops have been adhered to in copying original charters.

The use of capitals in the cartulary is so irregular that there has been no attempt to reproduce it, and the punctuation has been considerably simplified; the point (.) has, however, in general been represented by a colon (:). Original spelling has been retained, and also the cartulary use of ' $u$ ' and ' $v$ ', and ' $i$ ' and ' $j$ ', because these vary in the hands of the different scribes.

An attempt has been made to extend all reasonably certain contracted words, but where there is doubt, especially in the matter of proper names, no attempt has been made to extend, e.g., there is not sufficient evidence for a certain extension of Cant' either to its adjectival or noun form, as both forms have been found among the rare examples of its extension in original documents. Extensions of initials, and of words where there is slight doubt of their correct extension, are italicized. The descriptive headings to the entries are without exception rubricated throughout the cartulary, and these headings have also been printed in italics. 